\title{
A Median weighted product method for group decision support
}

\author{
Zö̈nabo SAVADOGO ${ }^{1 *}$, Stéphane Aimé METCHEBON TAKOUGANG ${ }^{2}$, Frédéric NIKIEMA $^{3}$ and Somdouda \\ SAWADOGO ${ }^{4}$
}

\author{
${ }^{1}$ Université Joseph KI-ZERBO, UFR-SEA/LANIBIO, Burkina Faso. E-mail : serezenab@yahoo.fr \\ ${ }^{2}$ Université Aube Nouvelle, Burkina Faso. E-mail: metchebon@gmail.com \\ ${ }^{3}$ Université Joseph KI-ZERBO,UFR-SEA/LANIBIO, Burkina Faso. E-mail: fredericnikiema0@ gmail.com \\ ${ }^{4}$ Institut Des Sciences (IDS), Burkina Faso. E-mail: somdouda@gmail.com \\ ${ }^{*}$ Corresponding author:Zö̈nabo SAVADOGO E-mail:serezenab@yahoo.fr
}

\begin{abstract}
When it comes to a multiple criteria and multiple actors decision-making problem known as a group decision support problem, the literature generally mentions two ways to aggregate the preferences of decision-makers to achieve consensual outcomes. The first class of group decision support methods run a same multi-criteria method for each decision-maker and thereafter, based on the individual result obtained, find a consensual result. The second class of methods first find a consensus on the preferences of decision-makers and then apply a multi-criteria method based on these consensual preferences to finally have a consensual result. In this work we propose a new method, belonging to the second class of methods for solving group decision problem. This method, called Median Weighted Product Method for Group Decision Support (MWPM-GDS) aims to achieve quickly and easily results that reflect as accurately as possible the choice of each decision-maker when solving group decision support problems. We applied the proposed method to two well-known examples in the literature and compared the results with those of two other group decision support methods to show its effectiveness.
\end{abstract}

Keywords: Multi-criteria aid; Group decision support; aggregation function; Median; Weighted product method

\section{Introduction}

Decision-making occupies a prominent place in any society. For instance deciding on where to place a back-up transformer is not an easy task. It involves factors that might be considered irrelevant or of little influence, but which in fact are extremely important and ensure the success of the location process [9]. Industrial organisations are constantly in search of new solutions and strategies to develop and increase their competitive advantage [4]. The central problem is how to evaluate a set of alternatives in terms of a number of criteria [22].

Multiple criteria decision-making (MCDM) is a procedure that combines the performance of decision alternatives across several, contradicting, qualitative and/or quantitative criteria and results in a compromise solution [16].

Multiple criteria and multiple actors decision making (MCMADM), known as group decision support is a MCDM process in which several decision-makers with different preferences should be taken into account and it intervenes more and more in many decisions making cases. It plays an important role in the real world. A large number of methods, theories and applications have been proposed to solve MCMADM problems [3].

In a classical group decision support (GDS) situation, there is a problem to solve, a solution set of possible alternatives or actions, and a group of two or more experts, who express their opinions about this solution set of alternatives [6].

The dynamics of the aggregation of individual decisions in a MCMADM problem has been a subject of central importance in decision theory [14].

In the group decision support literature, methods already exist for solving multi-criteria problems. But many of these methods incorporate the weighted sum.

According to many authors [2] [18] [21] although the weighted sum method is quite simple and easy to use, it suffers, nevertheless, from some difficulties relative to the choice of weight values and the "blind compensation" between criteria.

In this paper, we introduce a median weighted product method for group decision support (MWPM-GDS). MWPM-GDS is a new simple and fast method for solving group decision support problems by using the median and the weighted product allowing to limit the compensatory effect of the weighted sum and to obtain effective consensual results. We made some numerical applications and comparisons to two other group decision methods, namely Electre I for group decision support [13] and CHEMATRE [19] and we got interesting results. 
The rest of our paper is as follows. The second section presents two methods known in the literature: ELECTRE I method for group decision support, CHEMATRE method. The third section is dedicated to MWPM-GDS. In the fourth section, we apply the three methods mentioned above to two case studies. The fifth section deals with the comparison of results. Finally, the sixth section concludes our paper and provides guidance for further research.

\section{State of the art}

When it comes to a multiple criteria and multiple actors decision-making problem known as a group decision support problem, the literature generally mentions two ways to aggregate the preferences of decision-makers to achieve consensual outcomes. The first class of group decision support methods run a same multi-criteria method for each decision-maker and thereafter, based on the individual result obtained, find a consensual result. The second class of methods first find a consensus on the preferences of decision-makers and then apply a multi-criteria method based on these consensual preferences to finally have a consensual result. We refer to group decision methods belonging to the first and second class respectively as "consensus preference aggregation methods" and "consensus results aggregation methods".

\subsection{ELECTRE I method applied to the Group Decision}

ELECTRE I method has been extended to solve group decision support problem by using the two aggregation ways mentioned above. [13],[1] present each an extension of ELECTRE I for group decision support by using consensus preferences aggregation approach whereas [11] presents an extension of ELECTRE I method for group decision support by using consensus results aggregation methods approach. We invite the interested reader to see [11], [13], [1] for more details concerning these methods.

\subsection{Outline of CHEMATRE method}

- Define the matrix $w_{j}^{l}\left(\right.$ resp. $\left.g_{j}^{l}\right), l=1, \ldots, s$ and $j=1, \ldots, m$, intra-weight (resp. preference on criteria) for the $l^{t h}$ Decision-Maker (DM)

- Determine

$$
G_{l}(a)=\sum_{j=1}^{j=m} w_{j}^{l} g_{j}^{l}(a), \forall a \in A .
$$

- Calculate

$$
U(a)=\sqrt[s]{\prod_{l=1}^{s} G_{l}(a)}, \forall a \in A .
$$

- Operate comparisons:

$$
\begin{aligned}
& \forall a, b \in A \text { if } U(a) \geq U(b) \text { then } a \succsim b, \\
& \forall a, b \in A \text { if } U(a)=U(b) \text { then } a \equiv b .
\end{aligned}
$$

when equation (3) holds, it means that $a$ is preferred to $b$ and when equation (4) holds it means that alternatives $a$ and $b$ are indifferent. - Stop when all comparisons are made.

At the end, a complete or partial ranking is obtained in the set A of alternatives. The interested reader could see more details of the description of CHEMATRE in [19].

\section{Median Weighted Product Method for Group Decision Support (MWPM-GDS)}

We recall that the median of a statistical series is the number that divides this statistical series into two parts of the same size, the values of the character being arranged in the ascending order. The median is also the central value that minimizes the average value of absolute deviations [8] [15]. Hence its usefulness in the search for central value among the preferences expressed by decision-makers.

\subsection{Weighted Product Method (WPM)}

Suppose a given MCDA problem is defined on $m$ alternatives and $n$ decision criteria. In addition, suppose that all criteria are profit criteria, that is, the higher the values, the better. Next suppose that $w_{j}$ denotes the relative weight of the importance of the criterion $C_{j}$ and $a_{i j}$ is the performance value of the alternative $A_{i}$ when it is evaluated in terms of criterion $C_{j}$. Then, if we want to compare two alternatives $A_{K}$ and $A_{L}$ (where $m \geq K, L \geq 1$ ), the following product must be calculated:

$P\left(A_{K} / A_{L}\right)=\prod_{j=1}^{j=n}\left(a_{k j} / a_{l j}\right)^{w_{j}} \quad K, L=1,2,3, \ldots m$

If the ratio $P\left(A_{K} / A_{L}\right)$ is greater than or equal to the value 1 , then it indicates this action or alternative $A_{K}$ is preferred to the alternative $A_{L}$ (in the case of maximization). Note that if on the term $a_{k j}$ is null, then it is not taken into account in the product of the expression (5). If we want to determine the best solution, it is the one that is preferred to all the others. 


\subsection{Outline of MWPM-GDS}

To implement MWPM-GP, we proceed as follows:

- Step 1: For each criterion, we consider weights given by all the decision-makers and we retain the median which will represent the weight of this criterion at the calculation level with the WPM.

- Step 2: Similarly in each product stemming from formula (5), we consider the scores obtained with each decision-maker on each criterion and we retain the median score

- Step 3: Compute WPM by using median values stemming from Step 1 and Step 2

Assuming that the median achieves a good compromise between the preferences of decision-makers, it can therefore be said that MWPM-GDS belongs to the class of methods using consensus preferences aggregation approach.

\section{Numerical Experience}

\subsection{Example 1}

This example is taken from [20]. The problem is to find a better center for the management of severe cases of the covid-19 in Bukina Faso. For this, three decision-making committees (a covid-19 management unit, the Order of Doctors, the National Assembly) had the difficult task of evaluating four hospitals in the city of Ouagadougou/Burkina Faso (Yalgado hospital: Yalg hos, Bogodogo district hospital: Dist.Bog hosp, Tingandogo hospital: Ting hosp, peace clinic: clin.pe) on the basis of criteria (Equipment in respirators: Equi.Resp, Equipment in beds: Equi.Lit, Qualification of personnel: Qual.Pers, Quality of reception: Qual.Accu, Accessibility: Acces).

The data is provided by three (3) decision makers (or assigned to the criteria) in the form of scores between 0 and 10 . The range of the rating scales may differ from one decision maker to another, and each criterion is subject to 'a weighting coefficient expressing the importance of the criterion. The result obtained is a classification of hospitals containing alternatives (products) which must respect the following principle: "the hospital which is classified first must be accepted by the majority of decision-makers, and must not be rejected, even by one decision maker".

Each decision-making committee builds its assessment matrix. Suppose the different profiles are these:

Table 1: Judgments matrix of $D_{1}$ (the management unit)

\begin{tabular}{cccccc}
\hline & Equi.Resp & Equi.Lit & Qual.Pers & Qual.Accu & Acces \\
\hline min scale & 0 & 0 & 0 & 0 & 0 \\
max scale & 10 & 10 & 10 & 10 & 10 \\
\hline weight & 6 & 3 & 2 & 4 & 3 \\
\hline yalg hosp & 6 & 5 & 2 & 4 & 5 \\
dist.Bog hosp & 5 & 6 & 3 & 3 & 4 \\
Ting hosp & 7 & 5 & 4 & 6 & 3 \\
clin.pe & 6 & 4 & 5 & 3 & 6 \\
\hline
\end{tabular}

Table 2: Judgments matrix of $D_{2}$ (the medical order)

\begin{tabular}{cccccc}
\hline & Equi.Resp & Equi.Lit & Qual.Pers & Qual.Accu & Acces \\
\hline min scale & 0 & 0 & 0 & 0 & 0 \\
max scale & 10 & 10 & 10 & 10 & 10 \\
\hline weight & 7 & 5 & 3 & 3 & 4 \\
\hline yalg hosp & 7 & 6 & 2 & 3 & 3 \\
dist.Bog hosp & 6 & 5 & 2 & 5 & 3 \\
Ting hosp & 5 & 7 & 3 & 6 & 4 \\
clin.pe & 5 & 4 & 4 & 4 & 3 \\
\hline
\end{tabular}

\subsubsection{Resolution with MWPM-GDS}

Table 4 summarizes preferences of the three Decision Makers

Hence the final Table 5 gives median weights and median scores. 
Table 3: Judgments matrix of $D_{3}$ (the national assembly)

\begin{tabular}{cccccc}
\hline & Equi.Resp & Equi.Lit & Qual.Pers & Qual.Accu & Acces \\
\hline min scale & 0 & 0 & 0 & 0 & 0 \\
max scale & 10 & 10 & 10 & 10 & 10 \\
\hline weight & 6 & 4 & 2 & 3 & 3 \\
\hline yalg hosp & 6 & 5 & 2 & 4 & 4 \\
dist.Bog hosp & 7 & 6 & 3 & 5 & 3 \\
Ting hosp & 6 & 5 & 4 & 3 & 5 \\
clin.pe & 5 & 4 & 3 & 6 & 4 \\
\hline
\end{tabular}

Table 4: Synthesis of decision-makers' preferences

\begin{tabular}{cccccc}
\hline & Equi.Resp & Equi.Lit & Qual.Pers & Qual.Accu & Acces \\
\hline $\begin{array}{c}\text { min scale } \\
\text { max scale }\end{array}$ & 0 & 0 & 0 & 0 & 0 \\
\hline weight & 676 & 354 & 232 & 433 & 343 \\
\hline yalg hosp & 676 & 565 & 222 & 434 & 534 \\
$\begin{array}{c}\text { dist.Bog hosp } \\
\text { Ting hosp } \\
\text { clin.pe }\end{array}$ & 567 & 656 & 323 & 355 & 433 \\
\hline
\end{tabular}

Table 5: Median decision-makers' preferences

\begin{tabular}{cccccc}
\hline & Equi.Resp & Equi.Lit & Qual.Pers & Qual.Accu & Acces \\
\hline min scale & 0 & 0 & 0 & 0 & 0 \\
max scale & 10 & 10 & 10 & 10 & 10 \\
\hline median weight & 6 & 4 & 2 & 3 & 3 \\
\hline yalg hosp $\left(A_{1}\right)$ & 6 & 5 & 2 & 4 & 4 \\
dist.Bog hosp $\left(A_{2}\right)$ & 6 & 6 & 3 & 5 & 3 \\
Ting hosp $\left(A_{3}\right)$ & 6 & 5 & 4 & 6 & 4 \\
clin.pe $\left(A_{4}\right)$ & 5 & 4 & 4 & 4 & 4 \\
\hline
\end{tabular}


According to equation (5) and using data from Table 5, we make the following computations:

$$
\begin{aligned}
P\left(\frac{A_{1}}{A_{2}}\right) & =\left(\frac{6}{6}\right)^{6} \times\left(\frac{5}{6}\right)^{4} \times\left(\frac{2}{3}\right)^{2} \times\left(\frac{4}{5}\right)^{3} \times\left(\frac{4}{3}\right)^{3}=0.50<1, \\
P\left(\frac{A_{1}}{A_{3}}\right) & =\left(\frac{6}{6}\right)^{6} \times\left(\frac{5}{5}\right)^{4} \times\left(\frac{2}{4}\right)^{2} \times\left(\frac{4}{6}\right)^{3} \times\left(\frac{4}{4}\right)^{3}=0.07<1, \\
P\left(\frac{A_{1}}{A_{4}}\right) & =\left(\frac{6}{5}\right)^{6} \times\left(\frac{5}{4}\right)^{4} \times\left(\frac{2}{4}\right)^{2} \times\left(\frac{4}{4}\right)^{3} \times\left(\frac{4}{4}\right)^{3}=1.82>1, \\
P\left(\frac{A_{2}}{A_{3}}\right) & =\left(\frac{6}{6}\right)^{6} \times\left(\frac{6}{5}\right)^{4} \times\left(\frac{3}{4}\right)^{2} \times\left(\frac{5}{6}\right)^{3} \times\left(\frac{3}{4}\right)^{3}=0.96<1, \\
P\left(\frac{A_{2}}{A_{4}}\right) & =\left(\frac{6}{5}\right)^{6} \times\left(\frac{6}{4}\right)^{4} \times\left(\frac{3}{4}\right)^{2} \times\left(\frac{5}{4}\right)^{3} \times\left(\frac{3}{4}\right)^{3}=7.00>1, \\
P\left(\frac{A_{3}}{A_{4}}\right) & =\left(\frac{6}{5}\right)^{6} \times\left(\frac{5}{4}\right)^{4} \times\left(\frac{4}{4}\right)^{2} \times\left(\frac{6}{4}\right)^{3} \times\left(\frac{4}{4}\right)^{3}=24.60>1 .
\end{aligned}
$$

The calculations show that:

$A_{3}$ is preferred to $A_{4}$;

$A_{2}$ is preferred to $A_{4}$;

$A_{1}$ is preferred to $A_{4}$;

$A_{3}$ is preferred to $A_{2}$ which is preferred to $A_{4}$

$A_{3}$ is preferred to $A_{1} ; A_{2}$ is preferred to $A_{1}$.

So $A_{3}$ is the best followed by $A_{2}$ followed by $A_{1}$ followed by $A_{4}$. Using the ELECTRE I method and after calculating the matrices of concordances and discrepancies of each decision maker, the result is as follows: Tingandogo hospital is the best compared to other hospitals [12].

\subsubsection{Resolution with CHEMATRE}

Using this example with the CHEMATRE method, we obtain the results showed by Table 6 . Thus, the overall scores of the actions are:

Table 6: synthesis of CHEMATRE Method results

\begin{tabular}{ccccc}
\hline & $\sum_{j=1}^{j=5} w_{j}^{1} g_{j}^{1}\left(a_{i}\right)$ & $\sum_{j=1}^{j=5} w_{j}^{2} g_{j}^{2}\left(a_{i}\right)$ & $\sum_{j=1}^{j=5} w_{j}^{3} g_{j}^{3}\left(a_{i}\right)$ & $\sqrt[3]{\prod_{k=1}^{k=3} G_{k}\left(a_{i}\right)}$ \\
\hline yalg hosp & 96 & 106 & 84 & 94.90 \\
dist.Bog hosp & 78 & 100 & 96 & 90.80 \\
Ting hosp & 98 & 113 & 88 & 99.14 \\
clin.pe & 88 & 91 & 82 & 86.91 \\
\hline
\end{tabular}

94.90 for yalg hosp,

90.80 for dist.Bog hosp,

99.14 for Ting hosp,

86.91 for clin.pe.

This results show that Tingandogo hospital is the best compared to other hospitals. Finally the results obtain from the CHEMATRE and WPM methods are summarized in Table 7.

Table 7: synthesis of CHEMATRE Method results

\begin{tabular}{cc}
\hline CHEMASTRE & WPM \\
\hline$A_{3}$ & $A_{3}$ \\
$A_{1}$ & $A_{2}$ \\
$A_{2}$ & $A_{1}$ \\
$A_{4}$ & $A_{4}$ \\
\hline
\end{tabular}

\subsection{Example 2}

This example is taken from [11]. This problem involves choosing a partner from the following set: $A=\{$ Nippon Paint KK, Courtaoulds Coatings Holding, Kansai Paint, International Paint, US sec of navy $\}$. The set of criteria is $F=\left\{C_{1}, C_{2}, C_{3}, C_{4}\right\}$ with

$C_{1}$ : Product quality (Good, Fair, Bad),

$C_{2}$ : Technology (Good, Average, Bad),

$C_{3}$ : Cost (Francs), 
$C_{4}$ : Time.

A common preference scale for the four criteria was selected. Choosing a common preference scale greatly facilitates the assignment weights to criteria. Indeed changing a preference scale associated with a criterion requires to change the weight value of this criterion to have some kind of compensation.

The data are provided by the decision-makers (or assigned to the criteria) in the form of marks. The extend of the rating scales may differ from one decision maker to another, and each rating may be assigned a weighting factor. The result obtained, is a breakdown on set $A$ of shares (companies), one or several at least as good than others. The principle is as follows: the best solution should be accepted by as many people as possible, and should not be rejected too clearly, even by only one of them. Each decision maker builds his/her judgment matrix respectively shown in Table 8, Table 9 and Table 10.

Table 8: Matrix of judgments of D1

\begin{tabular}{ccccc}
\hline & Product quality & Technology & Time & Cost \\
\hline min scale & 0 & 0 & 0 & 0 \\
max scale & 10 & 10 & 10 & 10 \\
\hline weight & 3 & 4 & 3 & 5 \\
\hline NIPPON PAINT KK & 6 & 8 & 9 & 4 \\
COURTAULDS COATINS & 4 & 5 & 6 & 7 \\
INTERNATIONAL PAINT & 7 & 6 & 8 & 4 \\
KANSAI PAINT & 6 & 8 & 4 & 7 \\
US SEC OF NAVY & 5 & 4 & 7 & 6 \\
\hline
\end{tabular}

Table 9: Matrix of judgments of D2

\begin{tabular}{ccccc}
\hline & Product quality & Technology & Time & Cost \\
\hline min scale & 0 & 0 & 0 & 0 \\
max scale & 10 & 10 & 10 & 10 \\
\hline weight & 4 & 3 & 2 & 5 \\
\hline NIPPON PAINT KK & 7 & 5 & 3 & 8 \\
COURTAULDS COATINS & 3 & 6 & 8 & 4 \\
INTERNATIONAL PAINT & 6 & 8 & 4 & 3 \\
KANSAI PAINT & 5 & 4 & 6 & 7 \\
US SEC OF NAVY & 2 & 3 & 7 & 5 \\
\hline
\end{tabular}

Table 10: Matrix of judgments of D3

\begin{tabular}{ccccc}
\hline & Product quality & Technology & Time & Cost \\
\hline min scale & 0 & 0 & 0 & 0 \\
max scale & 10 & 10 & 10 & 10 \\
\hline weight & 4 & 5 & 3 & 5 \\
\hline NIPPON PAINT KK & 8 & 3 & 6 & 7 \\
COURTAULDS COATINS & 6 & 5 & 7 & 3 \\
INTERNATIONAL PAINT & 5 & 8 & 4 & 2 \\
KANSAI PAINT & 4 & 7 & 3 & 6 \\
US SEC OF NAVY & 7 & 6 & 5 & 8 \\
\hline
\end{tabular}

\subsubsection{Resolution by MWPM-GDS}

Considering the matrices of judgments of all the decision makers, we obtain the result presented in Table 11.

Table 12 shows median weights and median scores according to the whole criteria Also according to equation (5) we make the following 
Table 11: synthesis of decision-makers' preferences

\begin{tabular}{ccccc}
\hline & Product quality & Technology & Time & Cost \\
\hline $\begin{array}{c}\text { scale min } \\
\text { scale max }\end{array}$ & 0 & 0 & 0 & 0 \\
weight & 10 & 10 & 10 & 10 \\
\hline NIPPON PAINT KK & 344 & 435 & 323 & 555 \\
COURTAULDS COATINS & 636 & 853 & 936 & 487 \\
INTERNATIONAL PAINT & 765 & 565 & 687 & 743 \\
KANSAI PAINT & 654 & 688 & 844 & 432 \\
US SEC OF NAVY & 527 & 847 & 463 & 776 \\
\hline
\end{tabular}

Table 12: Median decision-makers' preferences

\begin{tabular}{ccccc}
\hline & Product quality & Technology & Time & Cost \\
\hline scale min & 0 & 0 & 0 & 0 \\
scale max & 10 & 10 & 10 & 10 \\
\hline median weight & 4 & 4 & 3 & 5 \\
\hline NIPPON PAINT KK $\left(B_{1}\right)$ & 7 & 5 & 6 & 7 \\
COURTAULDS COATINS $\left(B_{2}\right)$ & 4 & 5 & 7 & 4 \\
INTERNATIONAL PAINT $\left(B_{3}\right)$ & 6 & 8 & 4 & 3 \\
KANSAI PAINT $\left(B_{4}\right)$ & 5 & 7 & 4 & 7 \\
US SEC OF NAVY $\left(B_{5}\right)$ & 5 & 4 & 7 & 6 \\
\hline
\end{tabular}

computations:

$$
\begin{aligned}
P\left(\frac{B_{1}}{B_{2}}\right) & =\left(\frac{7}{4}\right)^{4} \times\left(\frac{5}{5}\right)^{4} \times\left(\frac{6}{7}\right)^{3} \times\left(\frac{7}{4}\right)^{5}=96.93>1, \\
P\left(\frac{B_{1}}{B_{3}}\right) & =\left(\frac{7}{6}\right)^{4} \times\left(\frac{5}{8}\right)^{4} \times\left(\frac{6}{4}\right)^{3} \times\left(\frac{7}{3}\right)^{5}=65.98>1, \\
P\left(\frac{B_{1}}{B_{4}}\right) & =\left(\frac{7}{5}\right)^{4} \times\left(\frac{5}{7}\right)^{4} \times\left(\frac{6}{4}\right)^{3} \times\left(\frac{7}{7}\right)^{5}=3.37>1, \\
P\left(\frac{B_{1}}{B_{5}}\right) & =\left(\frac{7}{5}\right)^{4} \times\left(\frac{5}{4}\right)^{4} \times\left(\frac{6}{7}\right)^{3} \times\left(\frac{7}{6}\right)^{5}=12.76>1, \\
P\left(\frac{B_{2}}{B_{3}}\right) & =\left(\frac{4}{6}\right)^{4} \times\left(\frac{5}{8}\right)^{4} \times\left(\frac{7}{4}\right)^{3} \times\left(\frac{4}{3}\right)^{5}=0.68<1, \\
P\left(\frac{B_{2}}{B_{4}}\right) & =\left(\frac{4}{5}\right)^{4} \times\left(\frac{5}{7}\right)^{4} \times\left(\frac{7}{4}\right)^{3} \times\left(\frac{4}{7}\right)^{5}=0.03<1, \\
P\left(\frac{B_{2}}{B_{5}}\right) & =\left(\frac{4}{5}\right)^{4} \times\left(\frac{5}{4}\right)^{4} \times\left(\frac{7}{7}\right)^{3} \times\left(\frac{4}{6}\right)^{5}=0.13<1, \\
P\left(\frac{B_{3}}{B_{4}}\right) & =\left(\frac{6}{5}\right)^{4} \times\left(\frac{8}{7}\right)^{4} \times\left(\frac{4}{4}\right)^{3} \times\left(\frac{3}{7}\right)^{5}=0.05<1, \\
P\left(\frac{B_{3}}{B_{5}}\right) & =\left(\frac{6}{5}\right)^{4} \times\left(\frac{8}{4}\right)^{4} \times\left(\frac{4}{7}\right)^{3} \times\left(\frac{3}{6}\right)^{5}=0.19<1, \\
P\left(\frac{B_{4}}{B_{5}}\right) & =\left(\frac{5}{5}\right)^{4} \times\left(\frac{7}{4}\right)^{4} \times\left(\frac{4}{7}\right)^{3} \times\left(\frac{7}{6}\right)^{5}=3.78>1 .
\end{aligned}
$$

It is deduced that Nippon Paint is the best followed by Kansai Paint followed by US SEC of NAVY followed by INTERNATIONAL PAINT followed finally by COURTAULDS COATINS.

After calculating the matrices of concordances and discrepancies of each decision maker, The ELECTRE I method for group decision chose Nippon Paint as the most interesting partner among the others [11].

\subsubsection{Resolution by CHEMATRE}

By applying the CHEMATRE method in this second example, the calculations conducted are given in table 13 . Thus, the overall scores of the actions are:

95.21 for NIPPON PAINT KK $\left(B_{1}\right)$,

78.12 for COURTAULDS COATINS $\left(B_{2}\right.$,

80.31 for INTERNATIONAL PAINT $\left(B_{3}\right)$,

88.35 for KANSAI PAINT $\left(B_{4}\right)$, 
Table 13: Synthesis of CHEMATRE Method results

\begin{tabular}{ccccc}
\hline & $\sum_{j=1}^{j=4} w_{j}^{1} g_{j}^{1}\left(a_{i}\right)$ & $\sum_{j=1}^{j=4} w_{j}^{2} g_{j}^{2}\left(a_{i}\right)$ & $\sum_{j=1}^{j=4} w_{j}^{3} g_{j}^{3}\left(a_{i}\right)$ & $\sqrt[3]{\prod_{k=1}^{k=3} G_{k}\left(a_{i}\right)}$ \\
\hline NIPPON PAINT KK & 97 & 89 & 100 & 95.21 \\
COURTAULDS COATINS & 85 & 66 & 85 & 78.12 \\
INTERNATIONAL PAINT & 89 & 71 & 82 & 80.31 \\
KANSAI PAINT & 97 & 79 & 90 & 88.35 \\
US SEC OF NAVY & 82 & 56 & 113 & 80.35 \\
\hline
\end{tabular}

80.35 for US SEC OF NAVY $\left(B_{5}\right)$.

We also see that Nippon Paint is the most interesting partner.

\section{Discussion}

In the first example, the CHEMATRE method ordered the hospitals in the following order: Tingandogo hospital is the $1^{s t}$, followed by of Yalgado hospital, followed by Bogodogo district hospital and finally by peace clinic.

The rankng of the MWPM-GDS is as follows: Tingandogo hospital is the best hospital, followed by Bogodogo district hospital, followed by Yalgado hospital, followed by peace clinic.

The ELECTRE I method for group decision has just shown that Tingandogo hospital is the best.

If we want to give importance to the fact that performance is less dispersed across all the criteria, then we can choose the MWPM-GDS Ranking; otherwise there is not enough argument to prefer the MWPM-GDS to the CHEMATRE method and vice versa.

However, it can be stressed that both the MWPM-GDS and CHEMATRE methods give the same best action (Tingandogo hospital) and the same worst action (peace clinic).

The difference in rank observed between the MWPM-GDS and CHEMATRE methods at the intermediate position level (between the best of the actions and the worst of the actions) shows their limit in the search for a robust ranking of all the actions.

In the second example, CHEMATRE ranked the partners as follows: Nippon Paint is the first followed by Kansai Paint followed by US of Navy followed by international paint followed by Courtaulds Coatins.

Regarding MWPM-GDS outcomes, we also have the same ranking as the CHEMATRE method. ELECTRE I method for group decision support just showed that Nippon Paint is the best partner.

The MWPM-GDS method does not use the weighted sum while CHEMATRE method does it. It can therefore be deduced that the MWPM-GDS method results in less compensation for poor performance on some criteria by high performance on other criteria. In addition MWPM-GDS is faster and easier to use than the two other methods.

Please also note that we did not discuss the results with the various decision-makers. This is a very important point because the result may not be the subject of consensus and requires a number of decision-making cycles during which the different decision-makers may be invited to review their preferences for new aggregations, which may lead to a more general consensus.

\section{Conclusion}

MWPM-GDS yielded results as good as those from CHEMATRE and ELECTRE I as they give the same best action to consider. In the first example, the MWPM-GD and CHEMATRE ranking are globally different but give the same best action (Tingandogo hospital) and the same worst action (peace clinic); they give the same ranking in the second example. We also note that there are less calculations at the MWPM-GDS comparing to CHEMATRE method and ELECTRE I for group decision support. In addition, The CHEMATRE method use the weighted sum as evaluation from each decision maker and the geometric mean to aggregate their preference. MWPM-GDS use median values coming from the decision-makers and then a pair wise comparison between actions based on weighted product is conducted. From a descriptive point of view, the MWPM-GDS method seem easier to use than ELECTRE I and CHEMASTRE. Also using the MWPM-GDS reduces the compensating effect of the weighted sum as occurs in CHEMASTRE, and does not require many calculations as in ELECTRE I. The question we can ask ourselves is this: if the values are very dispersed, the use of the median not play on the result when using MWPM-GDS for the decision group? In order words in which case MWPM-GDS for group decision is well appropriate? After using the median to have consensual preferences among decision makers, rather than using the weighted product method, others MCDM methods belonging to ELECTRE [17] [10] or PROMETHEE [5] family's methods could be used and the results compared.

\section{References}

[1] Agrebi, M, Méthodes d'aide à la décision multi-attribut et multi-acteur pour résoudre le problème de sélection dans un environnement certain/incertain : cas de la localisation des centres de distribution, Université de Valenciennes et du Hainaut-Cambresis (France) et Université de Sfax (Tunisie), (2018)

[2] Aissanou, F, "Décision multicritères dans les réseaux de télécommunications autonomes”, Télécom SudParis , France, (2012).

[3] B. Zhang B and D. Dong, "Consensus Rules with minimum adjustements for multiple attribute group decision making", Procedia Computer Science, volume 17,(2013), pp. 473-481

[4] Bertolini, M. and Bevilacqua, M. and Braglia, M. and Frosolin, M, "Quality and reliability Corner, An analytical method for maintenance outsourcing service selection", International Journal of quality and Reliability Management, volume 21, number 7,(2004), pp 772-788

[5] Ehrgott, M., and Figueira, J., "editors, Multiple Criteria Decision Analysis State of the Art Surveys",International Series in Operations Research Management Science Springer-Verlag, New York volume 233, pp. 187-220.

[6] Cabrerizo, F. J., Alonso, S., Pérez, I. J., and Herrera-Viedma, E, ”On consensus measures in fuzzy group decision making”, In Torra

[7] Narukawa, Y., "editors, Modeling Decisions for Artificial Intelligence", Lecture Notes in Computer Science, Springer,Berlin.

[8] Droesbeke, J. "Eléments de Statistique", Université Libre de Bruxelles, Ellipse, Paris,(1992). 
[9] Ferreira, R. J. P., De Almeida, A. T., and Ferreira, H. L. , "Multiattribute p-median model for location of back-up transformers", Brazilian journal of Operations and Production Management, 7(2),(2010).

[10] Figueira, J., Mousseau, V., and Roy, B. , "ELECTRE methods, In Figueira, J., Greco, S., and Ehrgott, M., editors, Multiple Criteria Decision Analysis: State of the Art Surveys", Springer Verlag,(2005).

[11] Ginting, R.,'Intégration du système d'aide multicritère et du système d'intélligence économique dans l'ère concurrentielle, application dans le choix de partenaires en Indonésie", PhD thesis, Université de droit et des sciences d'Aix-Marseille, France (2000).

[12] Ginting, R. and Dou, H., "L'approche multidécideur multicritère d'aide 'a la décision”, In Actes du colloque sur Les systèmes d'information elaborée, Société Fran caise de Bibliometrie Appliquée, France(1997).

[13] Hatami-Marbini, A. and Tavana, M. , "An extension of the electre i method for group decision-making under a fuzzy environment", Omega, 39,(2011).

[14] Hochbaum, D. S. and Levin, A., "Methodologies and algorithms for group-rankings decision", Management Science, 52(9)(2016).

[15] Härdle, W., Klinke, S., and Rönz, B., "Introduction to statistics”, Springer, Cham, Switzerland ,(2015).

[16] Kolios, A., Mytilinou, V., Lozano-Minguez, E., and Salonitis, K. , " A comparative study of multiple-criteria decision-making methods under stochastic inputs", Energies, 9(7), (2016).

[17] Maystre, L., Pictet, J., and Simos, J., " Méthodes multicritères ELECTRE. Description, conseils pratiques et cas d'application à la gestion environnementale", Presses polytechniques et universitaires romandes, collection Gérer l'environnement, Lausanne, Suisse,(1994)

[18] Roy, B., "Méthodologie multicritère d'aide 'à la décision”, Economica, Paris, (1985)

[19] Savadogo, Z., Ngoie, R.-B. M., Ulungu, B. E.-L., and Somé, B. : ”An aggregation function to solve multicriteria ranking problem involving several decision makers", International Journal of applied mathematical research, 3(4),(2014).

[20] Savadogo , Z. , Nikiema, F. , Sawadogo, S. , Somé, B. "Extension of the AHP method to group decision for determining the best care center of severe cases of Covid-19 in Ouagadougou/Burkina Faso: The case of three decision-makers", In actes of the $16^{t}$ h International Symposium on the Analytic Hierarchy Process (ISAHP 2020) /web conference, page 88, https://doi.org/10.13033/isahp.y2020.033,(2020)

[21] Simos, J., " Evaluer l'impact sur l'environnement: Une approche originale par l'analyse multicritère et la négociation", Presses Polytechniques et Universitaires Romandes, Lausanne,(1990).

[22] Triantaphyllou, E. "Multi-criteria decision making methods: A comparative study series", Applied Optimization, 44, ,(2000) 